\title{
Negotiating the politics of language
}

\author{
Language learning and civic identity in Wales
}

\author{
ROBIN MANN \\ University of Oxford, UK
}

\begin{abstract}
Since 2001, political concerns over social and ethnic cohesion have stimulated new debates over citizenship and belonging in the UK. A central feature of which has been a civic requirement of new citizens to learn English. Such a debate however coincides with concerns around in-migration in Wales, and the highly contested notion that non-Welsh speakers have a civic responsibility to learn Welsh. This article aims to explore the contradictions between these two cases via research with adult language learners in Wales - a group often ignored within literature on language, identity and citizenship. In analysing learners' discourses, the article identifies the ways in which learners come to terms with such notions of responsibility. However, the article argues that by positioning language learning in Wales in relation to the development of Welsh civic institutions, and by locating learning itself as a means of expressing such civic identification to place, so the demands for linguistic accommodation by monolingual English speakers may be increasingly articulated.
\end{abstract}

KEYWORDS adult language learning $\bullet$ civic responsibility $\bullet$ linguistic accommodation $\bullet$ Welsh Language

\section{LANGUAGE LEARNING AND CIVIC RESPONSIBILITY: UK AND WALES}

In October 2001, the Home Secretary of the day, David Blunkett, stimulated a debate over citizenship in the UK by suggesting that new immigrants to Britain should 'take citizen classes'. Under the reported plans, new citizens to the UK would be obliged to learn English and be 'schooled in British democracy and culture'. As David Blunkett states: 
... a political community can require new members to learn about its basic procedures and fundamental values ... I believe we need to educate new migrants in citizenship and help them to develop an understanding of our language, democracy and culture. (cited in Travis, 2001: 1)

This was clearly an attempt to establish a 'national home' in the aftermath of the riots in Bradford, Oldham and Burnley in northern England in the summer of 2001 and the events of ' $9 / 11$ ' later that year. In the weeks after 9/11, for instance, newspapers had been full of tales of 'British-born Muslims' with 'unmistakably British accents' talking of their desire to fight for the Taliban in Afghanistan. Most shocking of all for some, was that such declarations implied a sense of duty to Islam that overrides their affiliation to Britain (Guardian, 2001: 21). The need to instil a sense of belonging was also raised within the government-commissioned reports into the riots in the various cities of northern England. The main Cantle report commissioned by the UK Home Office, for instance, centred on 'the acute problems of segregation of, and lack of contact between, particular communities' as an underlying cause of the riots (Home Office, 2001: 28). It also recommended a greater expectation on the use of the English language amongst minority ethnic groups, as part of the defining of the rights, and responsibilities, of citizenship (Home Office, 2001: 19). In this context, the learning of English has played a central role in generating this sense of civic consciousness amongst new citizens (Blackedge, 2004). However, while these issues may be of fairly recent concern for the Westminster Labour Government, for Wales and Welsh-speaking communities, the issues of in-migration and language learning have been longstanding. Indeed, at the same time as English language learning proposals were being drawn up for new citizens to the UK, so debates surrounding the requirements for in-migrants to Wales to learn Welsh were also being revitalized.

In January 2001 for example, the question of English in-migration into the majority Welsh speaking communities was raised on a BBC Radio Wales talk show by one Plaid Cymru (Welsh Nationalist Party) councillor, Seimon Glyn, chairman of Gwynedd County Council's housing committee. As he states if they (the English) were coming here under strict monitoring and control, were made aware of the cultural aspects and made to learn Welsh there wouldn't be a problem ... They're coming here and you know frankly, they're telling us listen we're the new kids on the block and you do as we say now' (cited in Lamport, 2001: 1).

The contemporary debate took another turn when BBC's Question Time came to Caernarfon in February of 2001. During the programme the longstanding antagonism ${ }^{1}$ between the Labour Party in Wales and Plaid Cymru, not least on the question of the Welsh language, also re-emerged when Glenys Kinnock, a Labour MEP, challenged the then Plaid Cymru leader, Ieuan Wyn Jones, to dismiss Seimon Glyn from the party, along with his 'racist' remarks. The 'Seimon Glyn affair' was not the first occasion that the 
accusation of racism had been directed towards Welsh nationalism in general (see, for example, the exchanges between Denney et al., 1992; and Williams, 1994). What gave this particular episode an additional significance, was that it led to the establishment of a 'new' Welsh language pressure group Cymuned. Historically, Plaid Cymru and Cymdeithas Yr Iaith Gymraeg (The Welsh Language Society) have represented the main political voices of Welsh speaking communities (Rawkins, 1979). With Cymuned, however, a new group came to the fore, threatening to emerge as the most prominent agitator. Unquestionably, the recent English debate on citizenship has certain implications for the debate on newcomers to Wales. For instance, Cymuned has been able to justify its principles on the grounds that the Westminster Labour government has drawn up proposals regarding the need for newcomers to learn English: 'Cymuned believes that the Labour government ought to be consistent on this matter, making it clear that it is expected that newcomers into Welsh-speaking areas will learn Welsh' (Cymuned, 2001: 5). As one of Cymuned's founders, Simon Brooks, states: 'Blunkett is proposing far stronger measures [than we have in mind] to tie language in with citizenship ... I think we have a greater moral right to do that than he has because no one could begin to claim that the English language is in danger' (cited in Ward, 2002: 14).

In this article, I wish to examine these discourses surrounding citizenship and language learning, but to do so from the perspective of a group of Welsh learners. In doing so, I will present qualitative interview data from a case study of adult learners of Welsh in north-west Wales (which includes the county of Gwynedd). For this study, I had a specific interest in how notions of civic responsibility surrounding the maintenance of Welsh-speaking communities were considered by learners themselves and how these notions related to learners' own experiences of learning and using Welsh. Before turning to this directly, however, it is necessary to explore a little further why language learning within these respective contexts might be viewed so differently.

\section{LANGUAGE LEARNING AND LINGUISTIC ACCOMMODATION}

From what has been said thus far, it is evident how the parallel ' $U K$ ' and 'Welsh' debates about language learning and civic obligation occupy different positions within political discourse - as either promoting civic inclusion or as a form of nationalism or even racism. What, therefore, are the key points of difference between these two cases? What are the respective problems that non-accommodation is seen to pose in each case? By treating language learning as a form of accommodation, or as a means for ‘identity negotiation' (Pavlenko and Blackedge, 2004: 22), it is possible to 
examine how dominant relationships between language groups are either stabilized or destabilized.

A clear difference, for instance, is that, in Wales, Welsh-speakers are always Welsh/English bilingual. Conversely, at the UK level, it is immigrant ethnic minorities who are - or are required to be - bilingual, as opposed to the largely monolingual ethnic majority. One explanation for this disjuncture therefore is the way bilingual/minority language speakers - rather than monolingual/majority language speakers - are commonly held as principally responsible for accommodation (May, 2001). This, in part, reflects the 'power variable' that is often identified within empirical studies of linguistic accommodation. As Giles et al. (1991: 20) state, 'accommodation here may often be asymmetrical and unilateral towards the power source'. In other words, there is a propensity for those in subordinate positions to show greater convergence than those in dominant ones. For instance, Stanbach and Pearce (1981) have contended that blacks adapt communicatively to whites more than the converse due to the socioeconomic power of whites in the USA. In relation to Wales, therefore, it is because accommodation is demanded from majority English speakers that the requirement to learn Welsh is met with such resistance.

Allied to this is the way in which the threats posed by non-accommodation are also viewed within political discourse. Blackedge (2004: 68), for example, describes the 'symbolic association' that is made between minority Asian languages and social conflict within political discourses surrounding the 'race riots' of northern England in 2001. Along with government, the dominant institutions of media and education also play a critical role in determining whether demands made for the cultural adaption of new members receive widespread consent (Fairclough, 2001). As such, within political discourses at the UK level, it is logical and commonsensical that 'new citizens' and 'newcomers' should learn the dominant language and that failure to do so can result not only in social conflict but also exclusion from employment and civic participation. In Wales, however, the threats posed by non-accommodation are to do with concerns over the demise of a minority language and culture. An important difference between these respective cases therefore is their contradictory positions in relation to wider political and economic systems - namely, the nation state. Thus as May (2000:124) states, it is because 'minority language policies necessitate changes within a given nation-state to the balance of power relations between the linguistic groups and the languages they speak' that they are viewed as particularly problematic. Indeed it is also on this basis that:

... the unwillingness to learn Welsh must be predicated on the longstanding derogation and vitiation of minority languages ... it also helps to explain why so much of the oppositional discourse to bilingual policy continues to assume that any process of linguistic accommodation should remain the sole responsibility of minority languages speakers. (May, 2000: 123) 
Whilst concurring with this critique, it is also important to appreciate the 'situational anxieties' (Gardner, 1979) experienced by adult language learners. In attempting to accommodate and use Welsh in public, learners will often experience feelings of embarrassment and awkwardness. For adult language learners, learning is commonly an unstructured and ambiguous process with no set conclusion. Successful learning is also often dependent upon social relationships with first-language Welsh speakers (Newcombe and Newcombe, 2001). There are also significant class differences between those who learn and those who don't (McCoy, 1997). Indeed, as May (2000) identifies, notions of compulsion or obligation around learning Welsh are seen as far more acceptable when forming part of formal education systems rather than as a requirement for employment amongst adults. Thus, in relation to adult language learners, oppositions to learning Welsh would appear more complex than simply the reinstatement of a majority language hegemony. Rather, they call into question any simplistic labelling of particular groups as majority/minority or dominant/subordinate.

The terms majority and minority for instance are not simply questions of numerical size but also of power, and thus can shift with changes in relations of power between defined majority and minority groups (Eriksen, 1993; Juteau, 2004; Kaufmann, 2004). As Kaufmann states, 'dominance is sometimes achieved by minority groups as formerly centralized nation-states devolve power to regions or federal units' (2004: 6). And as Juteau (2004: 86) illustrates in the case of Quebec, the transformation from French Canadians as minority in both Quebec and Canada, to Quebecois as a nationally defined collectivity embodies a shift from a subordinate to a dominant majority. In the case of Wales, while, on one hand, English speaking majority attitudes remain highly durable (May, 2000), on the other, 'the process of the disintegration of the dominant group ... leaves a space for occupation by a diversity of new possibilities for society' (Mac Giolla Chriost, 2003: 21). In light of this de-centring of citizenship from the nation state, some forms of accommodation may be increasingly expected from majority language speakers. Thus, any argument around a requirement to learn Welsh should be seen as part of an increasing turn towards sub-state, localized and regionalized forms of civic identity in which linguistic accommodation is conceived as a more mutual and reciprocal process, and as a means by which people express a civic identification with their place of residence.

\section{THE CIVIC IDENTIFICATION OF WELSH}

As Mac Giolla Chriost states (2003: 83), the institutional reconfiguration of Britain through political devolution to Scotland and Wales ${ }^{2}$ opens up the possibility of a civic identification with the Celtic languages: 
One can suggest that it is in the context of the contemporary relocation of civic and ethnic values in relation to the political institutions of innovative politics characterized by a diffusion of sovereignty that new spaces are being opened up for language and identity. (2003: 89).

As Bourdieu (1991: 49) identified, the formation of European nation states during the 18th and 19th centuries marked the construction of an integrated 'educational and linguistic market', in which the symbolic, cultural and economic value of languages are accorded. As such, the current turns towards sub-state institutions in Wales points to a restructuring of linguistic markets to national or regional levels and an attendant renegotiation of the status attached to one's ability to use Welsh (see O'Riagian, 2001, for an analysis of the role of the Irish State in the revival of Irish).

In Wales, the last 40 years or so has seen a gradual institutionalization of bilingualism in the areas of education, media, governance and public life. ${ }^{3}$ Most important here has been the second Welsh Language Act (1993) and the establishment of the Welsh Language Board (1995) to ensure, through language schemes submitted by individual public bodies, that Welsh and English be treated on the basis of equality in the provision of services to the public in Wales. The Board also goes on to state that 'workplaces which have contact with the public in Wales seek access to sufficient and appropriately skilled Welsh speakers to enable those workplaces to deliver a full service through the medium of Welsh' (Welsh Language Board, 1995). While such legislations, along with the employment policies of certain local authorities, have been interpreted as social closure (Fevre et al, 1997), and to the exclusion of English-speaking Welsh people (Giggs and Pattie, 1992; Williams, 1985), it is important to stress that the place of Welsh in the labour market has been and remains a highly contested process, not least within bilingual public bodies themselves. In 1985, for instance, in the case of Jones and Doyle v. Gwynedd County Council, Gwynedd County Council, the Council representing one of the more Welsh speaking areas in Wales, was prosecuted under the 1976 British Race Relations Act for refusing a permanent position working with the elderly to two monolingual English speakers. ${ }^{4}$ More recently, has been the case of Carmarthen County Council, also representing a largely Welsh speaking area, and the longstanding dispute over the employment of non-Welsh speakers for a number of the Council's education posts.

At the same time, such legislation also calls into question any simplistic reading of Welsh and English as minority and dominant languages in Wales. Moreover, with the National Assembly for Wales's own commitment to mainstreaming Welsh within education and the public sector, as explicitly stated in its document Iaith Pawb (2003), along with its overall commitment to constructing a bilingual Wales, so notions of Welsh as a minority language in Wales - as opposed to a national language - are rendered increasingly problematic. Such developments, alongside political devolution, increas- 
ingly question any straightforward divisions between Welsh/bilingual minority and English/monolingual majority languages. In this context, therefore, I argue that it is necessary to consider the position of Welsh language learners, and their discourses around why notions of a responsibility to learn Welsh are problematic, in terms of these contradictions - as both 'privileged' and majority language speakers on the one hand, and yet who perceive themselves as 'outsiders' on the other.

\section{ADULT LEARNERS OF WELSH - THE RESEARCH}

The provision of Welsh learning courses for adults has formed an important part of the development of bilingual education in Wales over a number of decades (see Newcombe and Newcombe, 2001, for an overview). In 1993, a system of eight consortia was established in order to service geographical areas across Wales. Further to weekly classes taking place in further and higher education establishments, schools and village halls, many public bodies also provide in-house Welsh language courses (Welsh Language Board, 2001). The organization CYD (The Welsh Learners Society) also provides a social network for learners and opportunities for learners to use Welsh beyond classes. Furthermore, recent figures have shown an increase in the people registered on courses for learning Welsh - from 13,330 in 1994 and 19,320 in 1997 to 21,029 in 1998 (Welsh Language Board, 1999).

There are a number of factors, specific to Wales, that have contributed to this recent increase. First, such a rise coincides with the implementation of the 1993 Welsh Language Act as referred to above. This might not only require language training amongst employees and employers, but also encourage a perception amongst both Welsh and non-Welsh speakers of the employment benefits of learning Welsh. Secondly, and alongside this, has been the successful growth of bilingual and Welsh medium schools. Currently, around one-fifth of primary school pupils receive their education through the Welsh language and three-quarters learn Welsh as a second language. Such a growth may also encourage the learning of Welsh by parents themselves. Thirdly, there are indications of a change in public attitudes towards the Welsh language with evidence of greater support and goodwill towards its promotion (see NOP, 1995). There is also, more recently, considerable public and media representation of Welsh learners, particularly through television programmes such as Welsh in a Week and Cariad@Iaith on S4C (the Welsh language television channel) and the Learner Of The Year award at the annual National Eisteddfod.

Between June and November 2001, I conducted questionnaire-based 
interviews with 37 learners, followed by in-depth interviews with 20 learners selected from this initial group. All respondents were drawn from a summer school that took place within the Department of Continuing Education, University of Wales Bangor, and were purposively selected from a range of classes in order to gain respondents of different levels of ability and experience. While this constitutes a relatively small sample, it is possible to identify some of the key commonalities and differences between adult learners. In the questionnaire, learners were asked to provide details of their social backgrounds. The majority of these learners (28 out of 37 ) were of a professional status including around one-third (11) who were employees of the University. There is also a predominance of respondents from public and service sectors. The greatest proportion of learners had moved to Wales as adults (26, 21 of whom had moved from England) with 11 having been born and brought up in Wales. Of the 26 in-migrant learners, 13 had lived in Wales for over five years. Thirteen of the 26 in-migrant learners stated that they saw themselves as living in Wales for the remainder of their lives. Overall, around two-thirds of the group were in-migrant and of a middle-class, professional status. And while there is little available data on the demographic and social class background of learners in Wales, to validate this, my own conversations with tutors and co-coordinators of the programme suggests that the in-migrant and professional bias in this sample is largely indicative of learners undertaking this residential course within this region. Certainly, the prevalence of professional, in-migrant, learners would reflect the wider overrepresentation of English-born individuals in high-status occupational positions in north and west Wales (Day, 2002: 224). ${ }^{5}$ All this said, there are also important points of differentiation between learners in terms of their length of learning, their family and social networks with first-language Welsh speakers, and intentions to stay or move out of Wales. These numbers may also differ in contrasting areas of Wales. In areas such as the south Wales valleys for instance, we may find a higher proportion of Welsh-born learners. What I wish to focus on here, however, is the qualitative interviews conducted with a sub-set of this sample, and to investigate the different ways in which this particular group of learners might respond to those arguments that posit a requirement amongst non-Welsh speakers to learn Welsh.

The purpose of the follow-up interviews then was to pursue learners' discourses around notions of a requirement to learn Welsh and their resistance to this, and around their experiences of using Welsh in greater depth. Learners were asked whether they thought that they, as learners, or that incomers or even people in Wales generally, should learn Welsh and whether people have a responsibility to maintain the Welsh language. In the remainder of this article, I will provide an analysis of these discourses in order to explore the contextual and situated responses to notions of responsibility. 


\section{SENSES OF RESPONSIBILITY}

Well I have a lot of sympathy with them [respondent is referring to Cymuned, a Welsh language pressure group]. I think when you go into someone else's country you should do your best to learn the language in which you are living. I think it's important ... to at least learn the basics. (Female, University Lecturer, English-born)

Oh I definitely agree with that. I mean from living somewhere like Llyn and seeing places like Llanbedrog and Abersoch and seeing how those communities have pretty much died ... I think the emphasis should be placed on people to make an effort to learn . . . I mean I've got no excuse - born Welsh, I am Welsh and I should speak Welsh you know. (Male, IT Technician, Welsh-born)

I know a lot of people say its racist but I don't know because I think the death of a language is a very sad thing. Something that's been around for hundreds and hundreds of years and [to] see it disappearing in my generation is very upsetting ... I think there should be a monitoring of the influx of people who come over (Male, Teacher, Welsh-born)

I always felt that I'm missing something after being born Welsh and raised here ... and I want to do what I can to help ... I want my family to grow up with Welsh as a first language ... hopefully the process will become exponential. (Female, University Lecturer, Welsh-born)

The above statements exemplify largely positive attitudes towards the notion of a civic responsibility to learn Welsh. Such positive responses towards notions of a responsibility to learn were evident with the vast majority of respondents. Within these it is possible to identify a number of grounds upon which such a responsibility may be justified. For example, in the case of the first extract, we see the civic dimension of a responsibility to learn that manifests from going to live in 'someone else's country' and the importance of 'learning the language of the country in which you are living'. In the second and third extracts, however, we see a sense of responsibility emerging from the threat that non-accommodation poses towards the survival of Welsh as a local language. In these, along with the fourth extract, we also see a more emotionally charged response where 'the death of a language is a very sad thing' and 'is very upsetting'. There is also a personal sense of responsibility in which the respondents' sense of being Welsh comes in to play. In this case, there is a personal motivation to learning Welsh based around the respondents' sense of 'missing something' in being Welsh but not speaking Welsh. One can speculate here that the civicorientated discourse is more prominent amongst the in-migrant Welsh learner while Welsh-born learners articulated a more emotional or personal sense of obligation. At the same time, however, rarely were these commitments seen as unproblematic and such positive responses tended to be intertwined with certain reservations around this very notion. Indeed, just 
as a relationship between civic identity and learning Welsh may be articulated, then equally, it may be de-articulated:

I think Wales is moving away from the language with more emphasis on sustainability and conservation around its environment and I think because through my work with conservation I am able to contribute to preserving Welshness in that way. (Male, Conservation Officer, English-born)

What is significant in this case is how the respondent wishes to highlight other (non-linguistic) means of expressing a civic identity. In other words, 'just because people aren't learning Welsh doesn't mean they are not contributing'. In the above extract, the respondent is pointing to a sense of responsibility through a concern with conservation around the environment. Others also cited volunteering or investing in the local economy as ways of contributing, and thus ways of expressing a civic responsibility. Moreover, that 'Wales is moving away from the language' highlights the contingent relationships between language and identity (May, 2001). What is evident here, then, is how this contingency of language and Welsh identity provides a basis for negotiating a requirement to learn Welsh, because it represents merely one of many ways in which a commitment to one's place of residence may be expressed. This particular contingency also relates, however, to another significant theme around the need to recognize learners' personal circumstances.

\section{RECOGNIZING PERSONAL CIRCUMSTANCES}

I sort of appreciate that it's important not to lose the language but I feel if there's people like us who are trying our best to fit into society, we're not coming here and refusing to fit in with how things are, if we're trying to learn the language then that's fair enough as well ... I don't think you should expect everybody to learn because people have different reasons for doing it. I think in Menai Bridge or Bangor you don't notice it but as soon as you go into rural areas like Bethesda and small villages you really do notice it and it does become Welsh speaking country. (Female, Research Scientist, English-born)

We live in a row of cottages and nobody speaks Welsh ... maybe its because its so close to Bangor and the University ... and so I find the idea of a 'Welsh speaking community' a bit difficult because I don't know if I feel part of a community yet because I haven't actually joined things . . . but I don't think you can force it, I think that perhaps there are certain things in life that make you become more involved in a community such as having children ... (Female, Administrator, Scottish-born)

In these responses, we see reservations to the idea that 'everyone should learn' expressed through reference to the situated nature of one's personal 
motivations: 'people have different reasons for doing it', 'there are certain thing in life that make you become more involved in a community such as having children' and 'it depends where you live'. Indeed, a common theme throughout the interviews was that reasons for learning related largely to one's individual circumstances. These learners are also more critical of the idea of the 'Welsh speaking community', both in terms of its salience and in terms of their participation within it. Furthermore, learners were aware of local differentiation within the so-called 'Welsh speaking heartland', with some parts of the heartland viewed by those in surrounding areas as more or less 'Welsh': 'as soon as you go into rural areas . . . it really does become Welsh speaking country' (see also Thompson and Day, 1999 for an exploration of this). The suggestion being made here is that levels of responsibility or obligation within more 'English-speaking' areas are significantly reduced. On a more critical note, however, if learning Welsh represents a civic responsibility, then the particularities of one's local experiences of places are secondary. One can then identify this emphasis upon one's own particular situation and experiences of a 'Welsh-speaking community' as a discourse against the civic requirement to learn Welsh.

\title{
PERCEPTIONS OF EXCLUSION AND 'FEELING LIKE AN OUTSIDER'
}

\begin{abstract}
I'm always really uncomfortable with this kind of outsider thing with the awareness of being an outsider. I think that creating that kind of thing can be a bit negative. I think that as long as people who move here are willing to accept where they are moving to and to actually learn Welsh and to use it when they can you can't ask any more. (Female, Unemployed, English-born)
\end{abstract}

I live in Bethesda which is quite a Welsh speaking area so I do feel very English when I go down the shop for a pint of milk ... when I first moved there I did feel really English I suppose a bit like an outsider. But I'm glad I'm learning and I feel more at home as a 'Welsh learner' rather than an English person not making any effort ... I do feel that its appreciated (Female, Research Scientist, English-born)

I think by and large people are pleased that I'm learning and I can't say that I have ever been made to feel unwelcome or unaccepted ... however there are those who see it as a badge of exclusion and would be quite happy if no one else ever learned the language like a way of deliberately excluding ... for some I don't think anything would be good enough ... it's basically an exclusive band who have an interest in keeping you excluded. (Female, Retired, English-born)

What is interesting about these statements is that the learners talk about having an awareness of being an 'other' or about feeling like an 'outsider'. In the last of the above extracts, it is notable that the respondent doesn't 
point to any experience of being 'made to feel unwelcome or unaccepted' but is nevertheless aware of those 'who have an interest in keeping you excluded'. Indeed a commonality of all learners, Welsh-born and in-migrant alike, was a perception or a sense of being or feeling like an outsider. In the second of the above extracts, the learner refers to feeling like an outsider in relation to an experience of attempting to use Welsh. In this case, the association of Bethesda, a relatively large village some five miles from Bangor, as a Welsh-speaking place goes hand in hand with 'feeling English and a bit like an outsider'. Furthermore, being a Welsh learner 'rather than an English person not making any effort' is one that respondent feels more comfortable with. While not wanting to dismiss such feelings, one cannot, with interview data, take such stated perceptions of exclusion as reflections upon authentic experience. Rather, what appears to be taking place in these extracts is an awareness of the symbolic implications of language choice (for example, 'portraying oneself as a fluent Welsh speaker' or a 'desiring acceptance or approval') and the coming to terms with a new set of ideological pressures and sociolinguistic norms, as a result of which such feelings of exclusion are thrust upon them. Moreover, a perception of 'outsiderness' may be particularly prominent amongst those 'middle class in-migrant learners' who are 'generally well off, often retired, articulate and vocal and used to a situation whereby their cultural norm was that of the community in which they lived' (Davidson and Piette, 2000: 3).

\section{NEGOTIATING LINGUISTIC IDENTITIES}

Other research on learners in Wales has highlighted the local boundary processes of inclusion and exclusion that are at work in interactions between Welsh learners and first-language Welsh speakers (Bowie, 1993; Jones, 2000; Trossett, 1986, 1993). The study by Newcome and Newcombe (2001) argues that the responses of Welsh speakers towards learners attempting to use Welsh with them can be an important factor in successful outcome. Furthermore, that one of the most discouraging aspects of learning Welsh was that Welsh speakers would often switch to English either immediately or after a short period of trying to use Welsh. Jones (2000) also reports that 'in-migrants also reported a feeling that a few Welsh speakers associated Welsh as an "in-group" code and were therefore reluctant to use it with non-Welsh outsiders'. This interpretation suggests that Welsh speakers switching to English amongst non-Welsh speakers is primarily to do with the maintenance of cultural exclusion boundaries.

In interactions between native Welsh speakers and learners, consideration also needs to be given to what Woolard (1989), in her ethnographic research in Catalonia, refers to as the 'accommodation norm'. This refers to 
a traditional etiquette dating from the Franco years, a period in which the use of Catalan was often suppressed coercively, that it is proper to speak Catalan only to those who are known to be Catalan or for whom there are signals of Catalan Identity' (1989: 69). This is also similar to what Trossett (1993) refers to as 'linguistic politeness'. This leads speakers to converge not only on the learners' language proficiency, but also to their linguistic identity. In my own conversations with learners, for example, one highly proficient learner had talked about how he had always spoken Welsh with one local acquaintance, but that when this acquaintance had found out that he had learned Welsh as an adult, and had moved to Wales from England, his friend began to speak English to him rather than Welsh. Such norms of code switching therefore, while often based on a principle of accommodation, also serve to produce and reproduce linguistic boundaries. My own research here shows learners, in commenting on their own experiences of practising Welsh, to be acutely aware of the symbolic implications of language choice. As the following extracts show, learners were keen to demonstrate a sensitivity to these implications:

... if say we meet a member of her family or a family friend who I've never met before then she'll (learner's wife) speak to them in Welsh then she'll say 'this is

Paul my husband' in English, 'he doesn't know an awful lot of Welsh' and then they'll speak English and then I feel a bit guilty like you shouldn't have to speak English just because I'm here. (Male, Police Officer, Welsh-born)

When I first started here sometimes I would go into the canteen because you think you'll try and mix and get to know people and sometimes I'd go in and it was all admin Welsh speakers and I'd sit down and they'd all just carry on speaking Welsh and I'd feel a bit ooh what do I do now? Do I sit down and read the newspaper? Or start talking to them in English? Because at the time I hadn't started learning Welsh, so that was a but awkward, but then you think that's just their first language, that's just what's coming naturally to them, to all get together and be talking in Welsh, and it probably hasn't even crossed their minds that if you don't speak Welsh you can't join in. (Female, Administrator, English-born)

Both of the above responses suggest an acceptance of different norms of interaction within a bilingual context. In the first case, for example, the learner felt guilty that such code switching should occur on account of his own lack of fluency. In the second case, although the respondent felt unable to 'join in', it was justified on the basis that using Welsh was a 'natural' and 'normal' thing for Welsh speakers to do amongst themselves. As a result, her everyday interaction required negotiation. In addition, gaining an awareness of another person's background, and a resulting construction of identity, can modify everyday interaction. 


\section{CONCLUSION}

This article has sought to contribute to public and political debates around language learning and citizenship through considering the perspectives of Welsh language learners in Wales. A critical analysis of the parallel ' $U K$ ' and 'Welsh' debates surrounding citizenship and language learning in England and Wales has identified a key contradiction in how such demands are positioned within political discourse - as either promoting civic inclusion, or as a form of nationalism or even racism. Inherent to both these contexts is a monolingual bias in which it is bilingual minority speakers, as opposed to the monolingual majority, who are asymmetrically deemed as responsible for accommodation. Consequently, in the Welsh context, it is precisely because accommodation is being demanded from monolingual/ majority speakers that the requirement to learn Welsh is met with such mainstream opposition. However, the recent civic recognition of Welsh (May, 2000) alongside the redefining of citizenship through political devolution (Mac Giolla Chriost, 2003), creates the space for constructing a relationship between civic identity and the learning of Welsh. Thus the accommodation of Welsh by adult learners runs concurrently with the development of a civic Welsh identity that emanates from the growth of Welsh sub-state institutions.

For the learners within this study, language learning represented an important avenue for their own expressions of a civic responsibility towards Wales. What we gain, however, from the learners' talk are insights into the processes of inclusion and exclusion around language that are particularly acute within Wales. As this and other research (Bowie, 1993; Jones 2000; Trossett, 1993) has found, there is a strong perception amongst learners that those unable to use Welsh can be excluded from those community and social networks that are predominantly Welsh speaking. At the same time, it is vital to critically engage with such characterizations of learners, or non-Welsh speakers, as 'outsiders' or 'excluded'. Feelings of 'being like an outsider' can be attributed to a process of coming to terms with a new set of sociolinguistic norms around accommodation and non-accommodation. As such, the moving to the Welsh-speaking environs of north Wales forces difficult reflections upon one's own language behaviour and one's own right to remain a monolingual speaker.

The value of adult language learning in Wales is that it provides the opportunity for monolingual/English-speaking adults to engage in accommodative practices. Clearly, for linguistic accommodation to be mutual, rather than unilateral, then some form of accommodation by monolingual English speakers is also required. The concerns of Welsh language pressure groups, however, are around the effect that in- and out-migratory trends has on those spheres of social interaction within which Welsh takes precedence. 
Adult learners cannot, by themselves, provide much opposition to these trends, but they do contribute to a civic basis of linguistic belonging across the whole of Wales, in which increasing numbers, to varying degrees, will know at least some Welsh.

\section{Acknowledgements}

The author would like to thank Graham Day and the three anonymous referees for Ethnicities for their highly constructive comments and suggestions on earlier versions of this paper.

\section{Notes}

1 Such antagonisms between Plaid Cymru, the Welsh Nationalist Party, and the Labour Party in Wales can be seen to reflect historical divisions within Wales around which the interests of the English-speaking Welsh majority have been seen as largely antipathetic to the promotion of the Welsh language.

2 In 1997, both Scotland and Wales were granted political devolution in the form of the Scottish Parliament and the National Assembly for Wales. In the case of Wales, this arguably represents the most significant institutional development since the 1536-42 Acts of Union.

3 These include the first Welsh Language Act (1967); The Welsh Language Television Channel S4C (1982) and the Education Reform Act (1988) through which Welsh was established as a compulsory subject throughout all schools in Wales.

4 Note that this case was later overturned on appeal. The tribunal in this case concluding that an ability to speak a particular language could not, in itself, define membership of a particular ethnic group and thus could not amount to racial discrimination.

5 In fact, the concerns of the Welsh Language Society, and more recently Cymuned, around the in-migration of non-Welsh speakers is not only the threat that it poses to the place of Welsh within these areas, but also the rising land and house prices that is attendant upon this migration. It is thus in relation to this particular socioeconomic context that discourses around in-migration should be viewed.

\section{References}

Blackedge, A. (2004) 'Constructions of Identity in Political Discourse in Multilingual Britain', in A. Pavlenko and A. Blackedge (eds) Negotiation of Identities in Multilingual Contexts, pp. 68-92. Clevedon: Multilingual Matters.

Bourdieu, P. (1991) Language and Symbolic Power. Cambridge: Polity Press.

Bowie, F. (1993) 'Wales from Within: Conflicting Interpretations of Welsh Identity', in S. MacDonald (ed.) Inside European Identities: Ethnography in Western Europe, pp. 167-91. Providence, RI: Berg.

Cymuned (2001) Submissions by Cymuned to the Culture Committee [http://www. penllyn.com/cymuned/papurau/cym2.html].

Davidson, I. and B. Piette (2000) 'Without and Within: Inclusion, Identity and Continuing Education in a New Wales', paper presented at SCUTRA 30th 
Annual Conference 3-5 July, University of Leeds, UK [http://www.leeds.ac.uk/ educol/documents/00001441.htm].

Day, G. (2002) Making Sense of Wales: A Sociological Perspective. Cardiff: University of Wales Press.

Denney, D., J. Borland and R. Fevre (1992) 'The Social Construction of Nationalism: Racism and Conflict in Northwest Wales', Contemporary Wales 4: 149-65.

Eriksen, T.H. (1993) Ethnicity and Nationalism: Anthropological Perspectives. London: Pluto Press.

Fairclough, N. (2001) Language and Power. Harlow: Longman.

Fevre, R., D. Denney and J. Borland (1997) 'Class, Status and Party in the Analysis of Nationalism: Lessons from Max Weber', Nations and Nationalism 3(4): 559-77.

Gardner, R.C. (1979) 'Social Psychological Aspects of Second Language Acquisition', in H. Giles and R. St Clair (eds) Language and Social Psychology, pp. 193-220. Oxford: Basil Blackwell.

Giggs, H. and C. Pattie (1992) 'Wales as a Plural Society', Contemporary Wales 5: 25-64.

Giles, H., N. Coupland and J. Coupland, eds (1991) 'Accommodation Theory: Communication, Context and Consequence', in H. Giles et al. (eds) Contexts of Accommodation: Developments in Applied Sociolinguistics, pp. 1-68. Cambridge: Cambridge University Press.

Guardian (2001) 'Britain's Loyalty Test: Multicultural Values must be Defended', in The Guardian, 11 January, p. 21.

Home Office (2001) Community Cohesion: A Report of the Independent Review Team, Chaired by Ted Cantle. London: Home Office.

Juteau, D. (2004) “"Pure Laines” Quebecois: The Concealed Ethnicity of Dominant Majorities', in E.F. Kaufmann (ed.) Rethinking Ethnicity: Majority Groups and Dominant Minorities, pp. 84-101. London: Routledge.

Jones, K. (2000) "'Siarad Cymraeg pob cyfle": How and Why In-migrant Welsh Learners Use Welsh the way they do', in P.W. Thomas and J. Mathias (ed.) Developing Minority Languages: The Proceedings of the Fifth International Conference on Minority Languages, pp. 639-52. Cardiff: Wales: Gomer Press.

Kaufmann, E.F. (2004) 'Dominant Ethnicity: From Background to Foreground', in E.F. Kaufmann (ed.) Rethinking Ethnicity: Majority Groups and Dominant Minorities, pp. 1-14. London: Routledge.

Lamport, J. (2001) 'Voices of Hate', The Welsh Mirror, 18 January, p. 1.

McCoy, G. (1997) 'Protestant Learners of Irish in Northern Ireland', in A. Mac Poilin (ed.) The Irish Language in Northern Ireland, pp. 131-70. Ultach Trust: Belfast.

Mac Giolla Chriost, G. (2003) Language, Identity and Conflict. London: Routledge.

May, S. (2000) 'Accommodating and Resisting Minority Language Policy: The Case of Wales', International Journal of Bilingual Education and Bilingualism 3(2): 101-28.

May, S. (2001) Language and Minority Rights: Ethnicity, Nationalism and the Politics of Language. London: Longman.

National Assembly for Wales (2003) Iaith Pawb: A National Action Plan for a Bilingual Wales. Cardiff: Welsh Assembly Government.

Newcombe, L.P. and R.G. Newcombe (2001) 'Adult Language Learning: The Effect of Background, Motivation and Practice on Perseverance', International Journal of Bilingual Education and Bilingualism 4(5): 332-54. 
NOP (1995) Public Attitudes towards to the Welsh Language. London: NOP Social and Political.

O'Riagian, P. (2001) 'The Reproduction of Irish: 1986-1991', in J.A. Fishman (ed.) Can Threatened Languages be Saved?, pp. 195-214. Clevedon: Multilingual Matters.

Pavlenko, A. and A. Blackedge (2004) 'Introduction', in A. Pavlenko and A. Blackedge (eds) Negotiation of Identities in Multilingual Contexts, pp. 1-33. Clevedon: Multilingual Matters.

Rawkins, P. (1979) 'An Approach to the Political Sociology of the Welsh Nationalist Movement', Political Studies 27(3): 440-57.

Stanbach, M. and W.B. Pearce (1981) 'Talking to "The Man": Some Communicative Strategies used by Members of "Subordinate" Social Groups', Quarterly Journal of Speech 67(1): 21-30.

Thompson, A. and G. Day (1999) 'Situated Welshness: "Local" Experience and National Identity', in R. Fevre and A. Thompson (eds) Nation, Identity and Social Theory: Perspectives from Wales, pp. 27-47. Cardiff: University of Wales Press.

Travis, A. (2001) 'Citizenship Classes for Immigrants: Requirements to Learn English also Present in Blunkett's Reform Package' The Guardian, 26 October, p. 1.

Trossett, C. (1986) 'The Social Identity of Welsh Learners' Language in Society 15(2): 165-92.

Trossett, C. (1993) Welshness Performed: Welsh Concepts of Person and Society. Tucson, AZ: University of Arizona.

Ward, D. (2002) 'Wales Swamped by Tide of English Settlers', The Guardian, 1 March, p. 14.

Welsh Language Board (1995) Draft Guidelines as to the Form and Content of Schemes. Cardiff: Welsh Language Board.

Welsh Language Board (1999) The Welsh Language Factfile. Cardiff: Welsh Language Board.

Welsh Language Board (2001) All You Need to Know about Learning Welsh. Cardiff: Welsh Language Board.

Williams, G. (1994) 'Discourses on "Nation" and "Race", Contemporary Wales 6: 87-103.

Williams, G.A. (1985) When Was Wales? London: Penguin.

Woolard, K.A. (1989) Double Talk: Bilingualism and the Politics of Ethnicity in Catalonia. Stanford, CA: Stanford University Press.

ROBIN MANN is a Research Officer at the Oxford Institute of Ageing, University of Oxford. Address: Oxford Institute of Ageing, University of Oxford, 3rd Floor, Manor Road Building, Oxford, OX1 3UQ, UK. [email: robin.mann@ageing.ox.ac.uk] 